Revista Española de Antropología Americana ISSN: 0556-6533

https://doi.org/10.5209/REAA.61983

\title{
Obituario: Dr. Alfonso Lacadena García-Gallo, 1964-2018
}

El gremio académico de estudios mesoamericanos está de luto. El viernes 9 de febrero de este año de 2018 falleció uno de los investigadores más destacados de los estudios epigráficos mayas y nahuas, el Dr. Alfonso Lacadena García-Gallo, profesor e investigador de la Facultad de Geografía e Historia de la Universidad Complutense de Madrid.

El Dr. Lacadena nació en Zaragoza, España, en 1964, y desde muy joven mostró excepcionales dotes en el estudio de los antiguos sistemas de escritura mesoamericanos. Sus primeros trabajos se enfocaron en la escritura jeroglífica maya, un tema que investigó incansablemente a lo largo de su vida, legándonos numerosos artículos y ensayos que hoy día son referencia obligada para todos aquéllos que estudian el mundo maya, pues realizó importantes investigaciones en el campo de la lengua, gramática y literatura mayas jeroglíficas, ámbito donde ayudó a comprender la sintaxis nominal de las inscripciones cholanas y yucatecanas, el bilingüismo en los códices mayas, las voces pasiva y antipasiva en el idioma oficial de los escribas mayas, los gramemas usados para verbalizar o intransitivizar adjetivos o sustantivos, el complejo fenómeno de la diglosia en las Tierras Bajas mayas entre los siglos VII y VIII d. C., así como el origen histórico del silabario abierto de los mayas (consonante + vocal), que abreva de sistemas de escritura mesoamericanos más antiguos, como el epi-olmeca o istmeño. Aunado a ello, trazó rumbos a seguir en el desciframiento a medio plazo de este último sistema de escritura, identificando en el sistema maya temprano el uso y existencia de istmeñogramas, que son análogos a los sinogramas que contiene la escritura japonesa (los kanji), a los sumeriogramas que tiene la escritura acadia o a los acadiogramas que preservaban el luvita e hitita cuneiforme.

En su tesis doctoral, defendida en 1995, propone un método riguroso y preciso para estudiar las manos y los estilos caligráficos de los escribas mayas a lo largo del tiempo y del espacio, que no es sino la adaptación de la paleografía analítica latina, con todas las repercusiones que conlleva en el análisis, crítica y autenticación de textos antiguos. Ese trabajo le permitiría, cinco años después, establecer con precisión el número de amanuenses que configuraron el Códice de Madrid (manuscrito jeroglífico maya), así como las páginas y secciones que escribió cada uno.

Su erudición y constancia en el estudio de las escrituras indígenas americanas le llevó a revisar y analizar el sistema de escritura náhuatl. Su especialización en el campo de la gramatología (o ciencia de la escritura) le permitieron modernizar y sistematizar los trabajos pioneros que, sobre el tema, fueron iniciados en el siglo XIX por estudiosos de la talla de Joseph Marius Alexis Aubin, José Fernando Ramírez y Manuel Orozco y Berra. Su larga experiencia en el ámbito de la epigrafía maya, así como su relación con especialistas de distintos sistemas de escritura de la cuenca del Mediterráneo y del Cercano Oriente, a quienes conoció en el pasado, cuando estu- 
vo adscrito al Instituto de Estudios Islámicos y del Oriente Próximo, en España, le permitieron actualizar y sistematizar los métodos de estudio de los jeroglifos mayas y nahuas, proponiendo técnicas y refinamientos en la transliteración y transcripción de grafemas, detectando convenciones de subrepresentación (síncope y apócope) usadas por los escribas antiguos, recursos escriturarios propios de la región (amén del rebus y la complementación fonética), tales como el uso redundante de logogramas homófonos, así como refinadas y sutiles estrategias para representar la longitud o duración vocálica de las palabras mayas o las oclusivas glotales en el caso de los jeroglifos nahuas, sin contar el complejo tema de los procesos morfofonémicos.

La mayor parte de estas innovaciones en nuestra comprensión de los sistemas de escritura mesoamericanos deriva de la experiencia adquirida por el Dr. Lacadena en escrituras como la egipcia jeroglífica, la persa cuneiforme, la luvita jeroglífica, la lineal B micénica, el silabario chipriota y los alfabetos etrusco, griego y latino, mostrándonos lo mucho que el conocimiento sobre otros sistemas de escritura del mundo puede servirnos para entender el fenómeno de la escritura en la América precolombina. Su trabajo sobre los jeroglifos mayas y nahuas resulta impresionante; es minucioso y certero, una obra magistral a la talla de su erudición que constituye hoy un heraldo de la moderna epigrafía y del estudio científico de las escrituras indígenas americanas. Le debemos también un rico y profesional trabajo en el registro, dibujo y análisis de los textos escritos de Oxkintok, Ek Balam, Machaquilá y Naachtún, sitio, este último, donde aportó detalles inimaginables a la comprensión de textos jeroglíficos que hablan sobre la interacción de las élites mayas y teotihuacanas a finales del siglo IV d.C.

Fue uno de los protagonistas a nivel mundial en el desciframiento de la gramática maya jeroglífica (1998-2011), lo que le permitió incursionar en el ámbito del análisis literario de los textos jeroglíficos y alfabéticos mayas, considerándolos como un solo y mismo corpus escriturario (ca. 100 a.C.-2018), identificando un alto número de recursos, tropos y figuras retóricas, como el difrasismo, la metáfora, el paralelismo, la anáfora, la epífora, el isocolon, la sinécdoque, etcétera. Todo lo cual lo convirtió en el filólogo y traductor más sistemático que a nivel mundial haya tenido la epigrafía maya. En el ámbito de la traductología, además, siempre luchó por incluir la segmentación morfémica y las glosas morfológicas en el método crítico de la epigrafía maya, considerando que la traducción debe tomar en cuenta no solamente el léxico, sino también la gramática (morfología y sintaxis) de una lengua y de la otra, así como los fenómenos o matices que imprimen los recursos retóricos introducidos por los escribas mayas.

Pertenece a la generación de fundadores de las Conferencias Europeas de Mayistas Wayeb (1996-2018), organizando y fungiendo como anfitrión de las ediciones de 2003 y 2010, que se celebraron en Madrid. En el año 2011 la Universidad de Harvard le concedió el Premio Tatiana A. Proskouriakoff, en reconocimiento a sus múltiples aportaciones al conocimiento de las escrituras jeroglíficas maya y náhuatl, que es el equivalente más cercano que existe a un Premio Nobel en el área de los estudios sobre Mesoamérica. Y en octubre del año 2017 la Universidad Nacional Autónoma de México le rindió un sentido homenaje en el marco del III Encuentro Internacional de Gramatología.

La pérdida del Dr. Lacadena es irreparable, y deja un vacío en todos aquéllos que tuvimos la fortuna de conocerlo y ser honrados con su amistad. Aunado a sus múltiples aportaciones académicas, el Dr. Lacadena era un gran conversador y amante 
de la poesía, de los mariachis y de la música mexicana, que siempre nos transmitió la alegría y el entusiasmo por la vida, que tenía tiempo para todos los seres humanos con independencia de su nivel académico, que siempre supo hacer amigos y que conducía sus discrepancias intelectuales con otros colegas a través del camino de la concordia, de la amistad, de la caballerosidad y del respeto pues, como él decía, si algo pudo ver más allá de los ojos de sus amigos, era simplemente porque supo subir a los hombros de gigantes.

María Elena Vega Villalobos y Erik Velásquez García Universidad Nacional Autónoma de México 